\title{
Effects of cesium-substituted silicotungstic acid doped with polybenzimidazole membrane for the application of medium temperature polymer electrolyte fuel cells
}

\author{
Kyaw Zay $\mathrm{Ya}^{1}$, Pascal Nbelayim ${ }^{1}$, Wai Kian $\mathrm{Tan}^{2}$, Go Kawamura ${ }^{1}$, Hiroyuki Muto ${ }^{1,2}$, and \\ Atsunori Matsuda ${ }^{1 *}$ \\ ${ }^{1}$ Department of Electrical and Electronic Information Engineering, Toyohashi University of \\ Technology, 1-1 Hibarigaoka, Tempakhu-cho, Toyohashi, Aichi 441-8580, Japan \\ ${ }^{2}$ Institute of Liberal Arts and Sciences, Toyohashi University of Technology, 1-1 Hibarigaoka, \\ Tempaku-cho, Toyohashi, Aichi 441-8580, Japan
}

\begin{abstract}
Inorganic-organic composite membranes were prepared by using partly cesium-substituted silicotungstic acid (CHS-WSiA) and polybenzimidazole (PBI, MRS0810H) for medium temperature polymer electrolyte fuel cells (MT-PEFCs). Cesium hydrogen sulfate $\left(\mathrm{CsHSO}_{4}\right.$, CHS) and silicotungstic acid $\left(\mathrm{H}_{4} \mathrm{SiW}_{12} \mathrm{O}_{40}\right.$, WSiA) were milled to obtain 0.5 CHS-0.5WSiA composites by dry and wet mechanical millings. $N, N-$ dimethylacetamide (DMAc) was used as a disperse medium in the preparation of the inorganic solid acids by wet mechanical milling and also a casting agent for fabrication of membrane. Finally, flexible and homogeneous composite membranes with several phosphoric acid doping levels (PADLs) were obtained. The wet mechanical milling using DMAc was found to effectively promote good substitution of $\mathrm{H}^{+}$ion in WSiA by $\mathrm{Cs}^{+}$ion of CHS and promoted the formation of smaller grain sizes of composites, compared with dry milling. A high maximum power density of $378 \mathrm{mWcm}^{-2}$ and a good constant current stability test were obtained from a single cell test using the PBI composite membrane containing $20 \mathrm{wt} \%$ of 0.5 CHS- $0.5 \mathrm{WSiA}$ from wet milling and phosphoric acid doping level (PADL) of $8 \mathrm{~mol}$, at $150{ }^{\circ} \mathrm{C}$ under an anhydrous condition. Wet milling CHS-WSiA crystallites were highly dispersed in PBI to give homogenized membranes and played a significant role in the enhancemance of acidity by increasing the number of proton sites in the electrolyte membrane. After the addition of CHS-WSiA into PBI membrane, the acid and water retention properties were improved and incorporated as new proton conduction path by adsorbing phosphoric acid in these composite electrolyte membranes. These observations suggest that composite membranes with $8 \mathrm{~mol}$ of PADL are good promising PA dopedmembranes with effective electrochemical properties for the medium temperature fuel cells.
\end{abstract}

\section{Introduction}

Presently, environmental safety is of significant importance for human beings as well as the lives of future generations. One of the negative impacts of the environment is the large

\footnotetext{
${ }^{* 1}$ Corresponding author: matsuda@ee.tut.ac.jp
} 
usage of electrical energy which increases day by day. In our daily lives, people need energy, and the primary sources of energy are provided via the combustion of fossil fuels, which leads to high levels of air pollution and the emission of greenhouse gasses [1]. To solve these challenges, new energy production technologies have to be developed for future energy production. So, fuel cells are the great promise for new energy production. The fuel cell can make directly conversion from chemical energy to electrical energy as an electrochemical cell between fuels. Fuel cells are one of power generation with high interest because they can perform to enhance power conversion efficiency with a reduction of pollution levels. In particular, the electrolyte membrane is a main component in fuel cell performance to generate electrical power [2]. Polymer electrolyte membrane fuel cells (PEMFCs) contain perfluorosulfonic acid electrolyte such as Nafion ${ }^{\circledR}$ which is one of the most production methods of clean energy and are explored for usage as power sources for energy converters. They present positive characteristics, such as high performance like power density and conductivities, good efficiency and tolerance of pollutant levels. But, PEMFCs need humid condition for proton generation with low fuel cell performance and efficiency under the operating temperature $\left(<100{ }^{\circ} \mathrm{C}\right)$. So, to enhance the fuel cell performance and power efficiency for PEMFCs, a high operating temperature and kinematic reaction are required for high fuel cell efficiency [3-10]. After increasing the operating temperature $\left(>100{ }^{\circ} \mathrm{C}\right)$ for PEMFCs, they are improved with high kinematic reaction, higher tolerance for impurities in the fuel stream, and affable thermal-water maintainance. Polybenzimidazole (PBI) is the most attractive water insoluble polymer among the non-fluorinated ionomers (non-PFI) under active development because it shows good properties not only electronic but also as an ionic insulator. In addition, PBI have also attracted positive attention because of their high mechanical properties and thermal stablility. However, after pristine PBI membrane is doped with phosphoric acids (PA), mechanical strength of PBI membrane was reduced with the higher the acid content in PBI. And hence, PBI membranes with large amount of acid doping might happen higher acid leaching comparing with lower amount of acid doping PBI membrane in fuel cell applications. Inorganic composite doped-PBI membranes can make high tolerance acid leaching problems and enhance the proton conduction path in PBI [11-15].

Partially cesium-substituted heteropoly acids have attracted good interest due to their high catalytic properties with high proton conductivity in many acid-type reactions. Acidic or anhydrous inorganic compounds were mainly used for the performance enhancing of inorganic solid-state proton conductor. Inorganic solid-state composites produced by high mechanical milling treatment shows a high potential method that improves the proton conductivity of inorganic composite materials and reduces particle sizes [16-22]. Hence, fabrication of inorganic composites have been focused on the factors of low-cost, highperformance, medium temperature (at around $150{ }^{\circ} \mathrm{C}$ )-resistant for high temperature PEMFCs (MT-PEMFCs). Introducing solid acid composites (e.g. $\mathrm{CsHSO}_{4}-\mathrm{H}_{4} \mathrm{SiW}_{12} \mathrm{O}_{40}$ ) into the PBI membrane performs to improve absorption capability of PA and supports to prevent acid leaching of PA at high temperature [23].

In this research, CHS-WSiA composite was created to enhance the anhydrous proton conductivity and reduce the particle sizes via wet mechanical milling as inorganic fillers for the application of membrane fabrication. For the MT-PEMFCs, proton conductivities and cell performances of CHS-WSiA/PBI membranes were improved after fabrication of composites doped-PBI. 


\section{Experimental Procedure}

Reagent grade cesium hydrogen sulfate $\left(\mathrm{CsHSO}_{4}, \mathrm{CHS}\right)$ (Sokawa Chemical Co.Ltd., Japan) and silicotungstic acid $\left(\mathrm{H}_{4} \mathrm{SiW}_{12} \mathrm{O}_{40}, \mathrm{WSiA}\right)$ (Wako Pure Chemical Industries, Japan) were purchased to fabricate CHS-WSiA composite materials. To synthesize 0.5CHS-0.5WSiA dry composite materials, the planetary dry milling was carried out under a dry nitrogen atmosphere using a planetary ball mill (Purverisette 7, Fritsch) with an agate pot (45 mL) and agate balls (10 balls of $10 \mathrm{~mm}$ diameter) at $720 \mathrm{rpm}$ and a rotation ratio of 1:1 for $1 \mathrm{~h}$. After dry milling, these composites were collected from the mechanical milling pot and were heated at $80^{\circ} \mathrm{C}$ in a vacuum oven overnight to obtain dry and fine composite powders. On the other hand, to fabricate $0.5 \mathrm{CHS}-0.5 \mathrm{WSiA}$ wet composites, $N, N$-Dimethylacetamide (DMAc, $5 \mathrm{~mL}$ ) (Wako; $99 \%$ ) was used as solvent/disperse media at $300 \mathrm{rpm}$ for $1 \mathrm{~h}$. After mechanochemical wet milling, the composite precursors were dried at $60{ }^{\circ} \mathrm{C}$ overnight in an oven to remove hydrated water and DMAc from the sample. Then, it was also heated at $80{ }^{\circ} \mathrm{C}$ for $3 \mathrm{~h}$ in a vacuum oven to obtain more dry and fine composite powders. A schematic diagram for $x \mathrm{CHS}-(1-x) \mathrm{WSiA}$ composites produced by wet mechanical milling method was shown in Fig 1[24,25].

For electrolyte membrane fabrication, DMAc $(43.23 \mathrm{~g})$ and polybenzimidazole solution (PBI, MRS0810H) $(1 \mathrm{wt} \%, 4.8 \mathrm{~g})$ were used to cast pristine PBI membrane.

Before membrane casting, a magnetic stirrer and a sonicator were used to stirr PBI solution at $500 \mathrm{rpm}$ for $1 \mathrm{~h}$ and sonicate for $30 \mathrm{~min}$. Then, petri dish $(\varphi=9.7 \mathrm{~cm})$ was used to cast PBI membrane solution under the temperature $\left(60-120{ }^{\circ} \mathrm{C}\right)$ for $24 \mathrm{~h}$ drying. Hot-water durability test was also performed for PBI membrane to eliminate residual materials and DMAc solvent at $90{ }^{\circ} \mathrm{C}$ for $5 \mathrm{~h}$. Finally, it was dried to evaporate hydrated water from membrane under dry temperature $\left(\right.$ at $\left.60{ }^{\circ} \mathrm{C}\right)$ overnight.

$20 \mathrm{wt} \%$ of CHS-WSiA composites was added into PBI solution to fabricate CHSWSiA/PBI membranes under the same fabrication method of pristine PBI membrane, at weight percent (PBI:CHS-WSiA, 5:1 wt \%), before casting.

Finally, PA doping of CHS-WSiA/PBI membranes and pristine PBI membrane was performed by immersing into $85 \%$ of PA (Wako) and heated at $60{ }^{\circ} \mathrm{C}$ for desired PA doping levels (PADLs). Prior to conductivity and fuel cell measurement, PA doped membranes were heated at $60^{\circ} \mathrm{C}$ for $1 \mathrm{~h}$ to eliminate excess PA and water.

X-ray diffraction (XRD; RINT 2200, Rigaku) patterns of the mechanochemically fabricated Cs-substituted WSiA composites from dry and wet milling were evaluated at room temperature (RT).

The morphologies of the CHS-WSiA composite powders, CHS-WSiA/PBI membranes, and pristine PBI membrane were measured by using field emission scanning electron microscopy (FE-SEM; S-4800, Hitachi).

AC impedance spectroscopy measurement was performed to evaluate temperaturedependent proton conductivities of all membranes over a frequency range of $10^{7}-1 \mathrm{~Hz}$ (Solartron; SI 1260) under dry nitrogen condition. Before conductivity measurement, composite samples and electrolyte membranes were kept at $150{ }^{\circ} \mathrm{C}$ for $1 \mathrm{~h}$ under $\mathrm{N}_{2}$ atmosphere. For membrane electrode assemblies (MEAs), commercially $0.5 \mathrm{mg} \mathrm{cm} \mathrm{cm}^{-2}$ Pt-loaded carbon papers were used as electrodes. Pt-loaded carbon sheets were prepared the sizes $\left(1 \times 1 \mathrm{~cm}^{2}\right)$ and $\left(1.5 \times 1.5 \mathrm{~cm}^{2}\right)$ for anode and cathode, respectively.

The membranes with PA doping were sandwiched by the Pt-loaded carbon catalysts to set MEAs measurement condition. $100 \mathrm{~mL} \mathrm{~min}^{-1}$ of $\mathrm{H}_{2}$ and $100 \mathrm{~mL} \mathrm{~min}^{-1}$ of $\mathrm{O}_{2}$ were applied to supply during FC evaluation. Operating temperature was selected at $150{ }^{\circ} \mathrm{C}$ for single fuel cell test under dry condition $[24,26]$. 
Wet milling

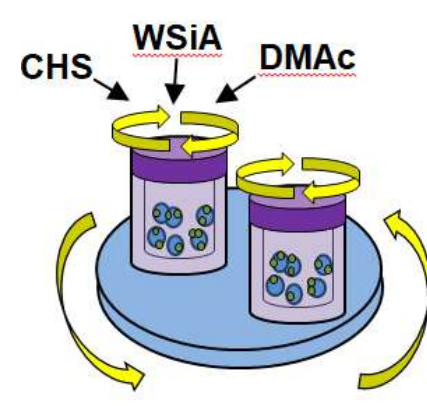

Before heating

After heating

Fig. 1. Schematic diagram for $0.5 \mathrm{CHS}-0.5 \mathrm{WSiA}$ composites produced by wet mechanical milling method.

\section{Results and discussion}

\subsection{Characterization of $0.5 \mathrm{CHS}-0.5 \mathrm{WSiA}$ composites via dry and wet mechanical milling}

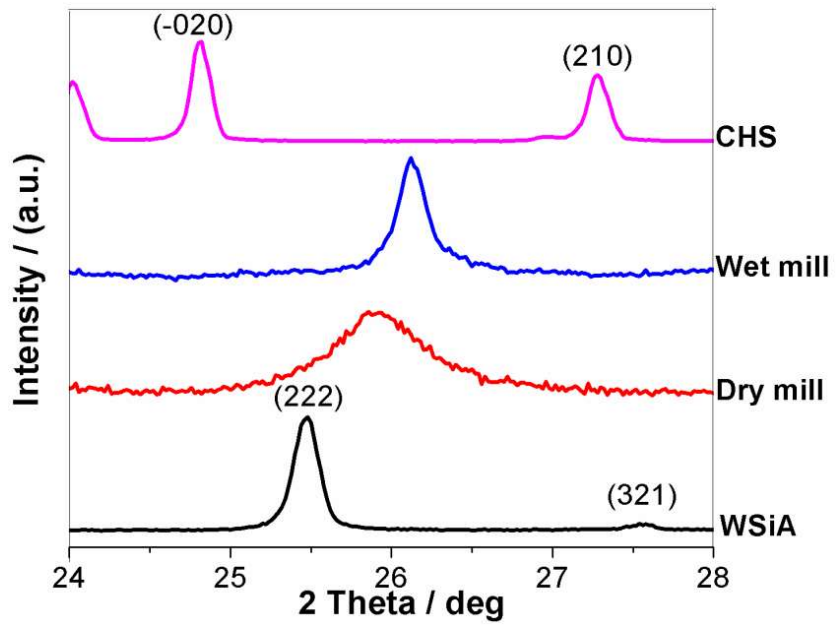

Fig. 2. Powder XRD patterns of WSiA, CHS, 0.5CHS-0.5WSiA (dry milling) and 0.5CHS$0.5 \mathrm{WSiA}$ (wet milling) composites.

From XRD measurement, 0.5CHS-0.5WSiA (dry and wet milling) inorganic composites are shown in Fig. 2. Prior to mechanical milling, diffraction peaks of CHS and WSiA in Fig. 2 were well matched with standard JCPS library file. After mechanical dry milling to fabricate $\mathrm{Cs}_{\mathrm{x}} \mathrm{H}_{4-\mathrm{x}} \mathrm{SiW}_{12} \mathrm{O}_{40}$, noticeable changes are detected in the XRD results from $25.6^{\circ}$ to $26^{\circ}$; and it showed broad diffraction peak comparing with composite fabricated from mechanical wet milling. After mechanical wet milling, the diffraction peak of composite slightly shifted to higher angle; that compared with composite from mechanical dry milling. Both composites synthesized by dry and wet milling showed the highest intensities with the high peak shifting to higher angles which indicates that the $\mathrm{H}^{+}$ion in WSiA was partly substituted with large $\mathrm{Cs}^{+}$ion in CHS to fabricate $\mathrm{Cs}_{\mathrm{x}} \mathrm{H}_{4-\mathrm{x}} \mathrm{SiW}_{12} \mathrm{O}_{40}$ via mechanical dry and wet milling. 


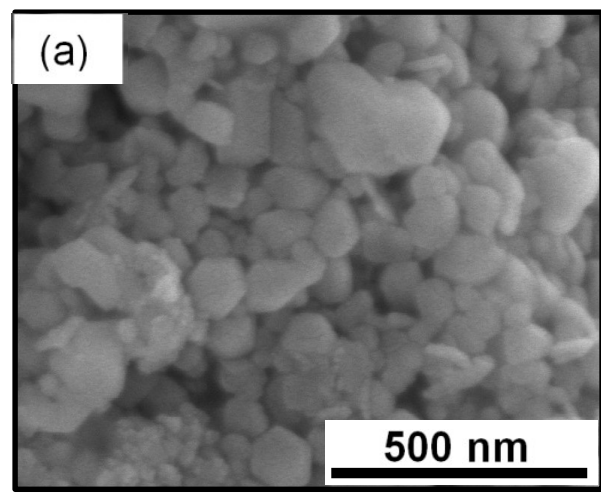

Fig. 3. FE-SEM images of (wet milling) composites.

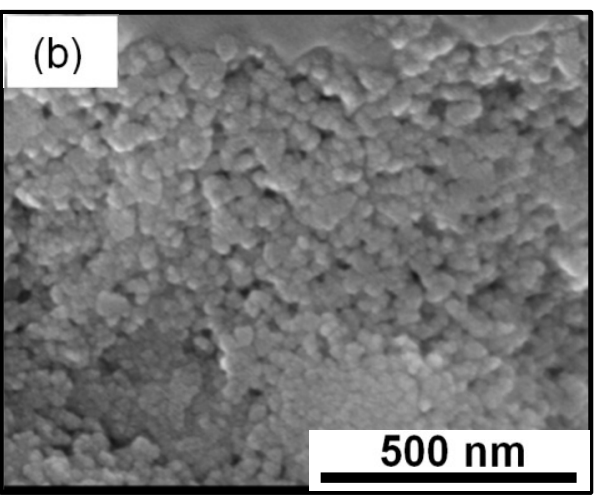

(a) 0.5CHS-0.5WSiA (dry milling) and (b) $0.5 \mathrm{CHS}-0.5 \mathrm{WSiA}$

Fig. 3(a) and 3(b) show FE-SEM images of 0.5CHS-0.5WSiA (dry milling) and 0.5CHS$0.5 \mathrm{WSiA}$ (wet milling) composites. After mechanochemical dry and wet milling, it was seen that the chemical reaction was formed between CHS and WSiA to produce Cs-substituted WSiA composite materials with high proton percolation. 0.5CHS-0.5WSiA (dry milling) and 0.5CHS-0.5WSiA (wet milling) composites showed surface homogeneous and spherical structure as fine composite powders. While 0.5CHS-0.5WSiA (dry milling) composite showed grain sizes at about $50 \mathrm{~nm}, 0.5 \mathrm{CHS}-0.5 \mathrm{WSiA}$ (wet milling) composite showed at about $20 \mathrm{~nm}$ as the grain units. The grain sizes of $0.5 \mathrm{CHS}-0.5 \mathrm{WSiA}$ (wet milling) composites were smaller than 0.5CHS-0.5WSiA (dry milling) composites via a high chemical reaction between CHS and WSiA with the help of DMAc solvent. Composite samples with small particles will support to be a large active surface area and take more acid, which shows good properties of the composites. 0.5CHS-0.5WSiA (wet milling) composites showed good distribution which is more compact than 0.5CHS$0.5 \mathrm{WSiA}$ (dry milling) because of the effective DMAc solvent's treatment. According to mechanochemical wet milling, this solvent helps to make an effective chemical reaction between the raw samples and supported to achieve a high proton conduction path in composites.

\subsection{Characterization of CHS-WSiA/PBI and pristine PBI membranes}

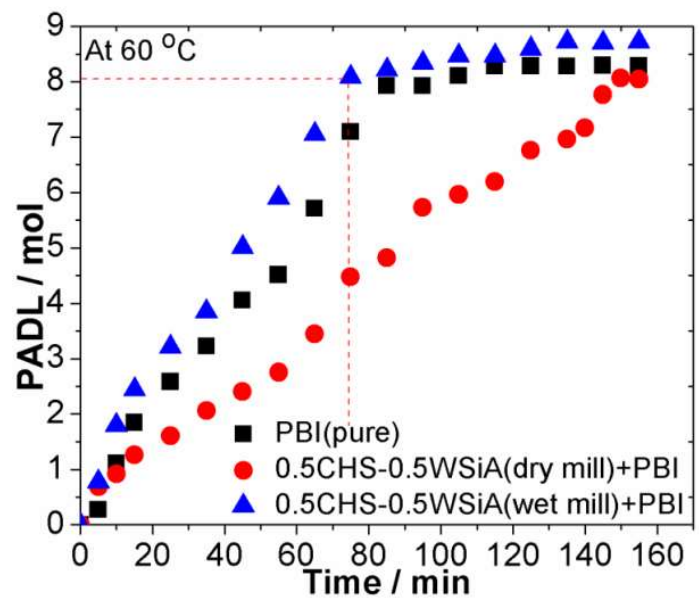

Fig. 4. Time-dependent of PADL for pristine PBI, 0.5CHS-0.5WSiA(dry mill)/PBI, and 0.5CHS$0.5 \mathrm{WSiA}$ (wet mill) /PBI membranes, respectively. 
Different PADL values of CHS-WSiA/PBI and pristine PBI membranes with different doping time were shown in Fig. 4. For CHS-WSiA(wet)/PBI electrolyte film, after 35 min, PADL value was reached to $4 \mathrm{~mol}$, and $6 \mathrm{~mol}$ for $55 \mathrm{~min}$, and then reached to $8 \mathrm{~mol}$ during $70 \mathrm{~min}$ for FC evaluation. Then, it was slightly increased to be $8 \mathrm{~mol}$ over $70 \mathrm{~min}$ during PA doping time. $8 \mathrm{~mol}$ of PADL was selected to apply for membrane characterization and FC evaluation. On the other hand, after $65 \mathrm{~min}, 4 \mathrm{~mol}$ of PADL was achieved for the CHSWSiA(dry)/PBI membrane, and $6 \mathrm{~mol}$ for $105 \mathrm{~min}$, and then, reached to 8 mol PADL during $150 \mathrm{~min}$. For pristine PBI, it showed $4 \mathrm{~mol}$ of PADL within $8 \mathrm{~min}$, and reached to $6 \mathrm{~mol}$ during $70 \mathrm{~min}$, and then saturates $8 \mathrm{~mol}$ PADL after $85 \mathrm{~min}$. Especially, PA dopants in composite PBI membranes and pristine PBI exist in different forms. For instance, they exist not only chemically reacted PA with nitrogens of imidazole rings in PBI but also physically adsorbed PA in PBI as free acids [10]. CHS-WSiA (wet)/PBI membrane with nonosized-composite materials showed good hygroscopic properties and maintained a large amount of PA after PA doping.
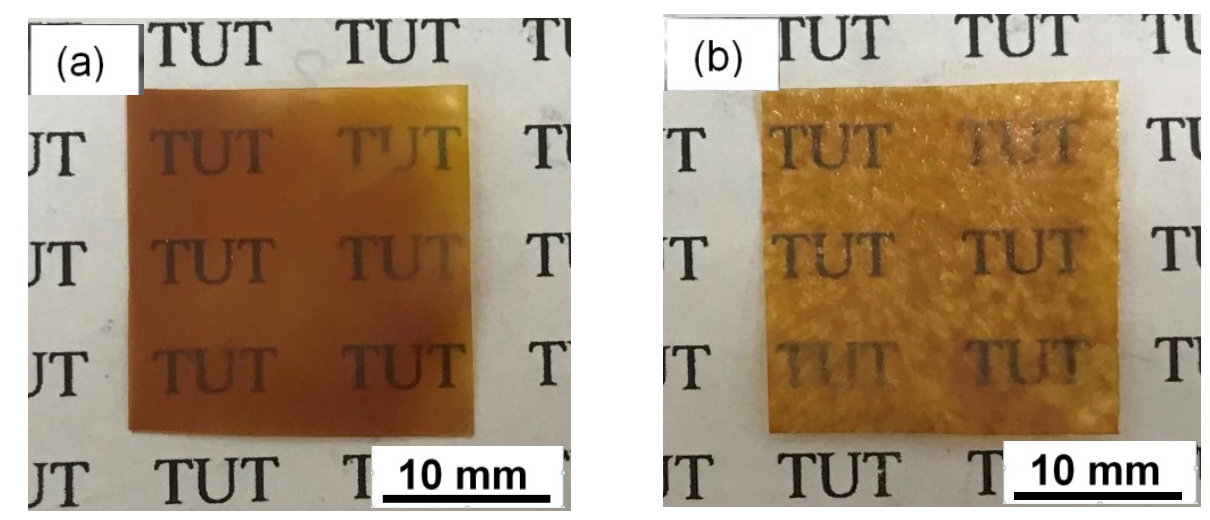

Fig. 5. Photographs of (a) 0.5CHS-0.5WSiA (dry mill)/PBI membrane and (b) 0.5CHS-0.5WSiA (wet mill) /PBI composite membranes.
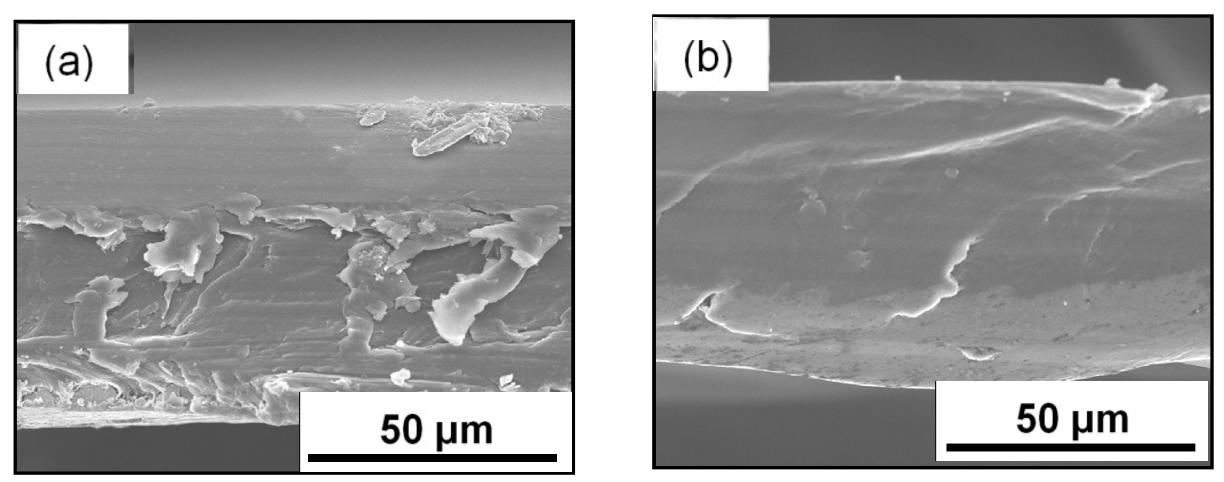

Fig. 6. Cross-sectional FE-SEM images of (a) 0.5CHS-0.5WSiA (dry mill)/PBI and (b) 0.5CHS$0.5 \mathrm{WSiA}($ wet mill)/PBI composite membranes. 
Photographs of $0.5 \mathrm{CHS}-0.5 \mathrm{WSiA}$ (dry mill) and $0.5 \mathrm{CHS}-0.5 \mathrm{WSiA}$ (wet mill) composite electrolyte membranes are shown in Fig. 5. They both were seen to be good transparent and homogenous appearances. FE-SEM morphologies of cross-sectional measurements of the composite membranes were shown in Fig. 6 with the typical thickness of 50-70 $\mu \mathrm{m}$ for the composite membranes; and they showed inorganic composite materials were thoroughly dispersed in PBI matrix after fabrication of CHS-WSiA/PBI composite membranes. These observations suggested that the homogeneous and thin membranes with sufficient thickness were convenient to apply for anhydrous conductivity measurements and FC performance evaluation.

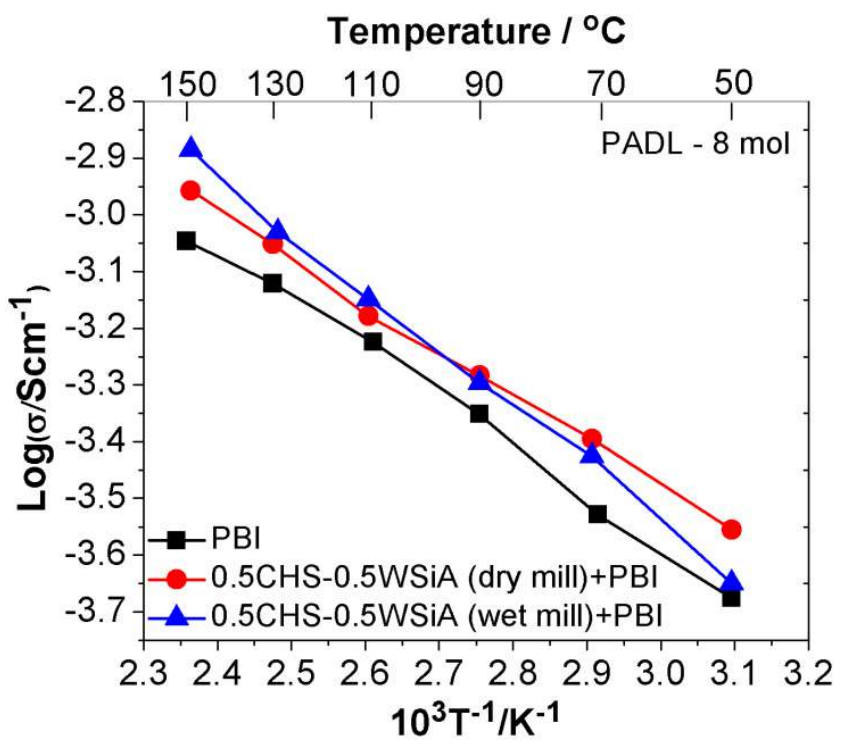

Fig. 7. Temperature dependence of conductivity of pristine PBI membrane, 0.5 CHS- $0.5 \mathrm{WSiA}$ (dry mill)/PBI and $0.5 \mathrm{CHS}-0.5 \mathrm{WSiA}$ (wet mill) /PBI composite membranes under anhydrous condition.

Anhydrous proton conductivities of pristine PBI and CHS-WSiA/PBI composite electrolyte membranes were measured along the temperature range $50-150{ }^{\circ} \mathrm{C}$. Figure 7 shows the temperature-dependent conductivity measurements of pristine PBI and composite PBI membranes with $8 \mathrm{~mol}$ of PADL. The conductivity's trends of all membranes were increasing with increasing the temperature in the range 50 to $150{ }^{\circ} \mathrm{C}$. However, the conductivity values of the CHS-WSiA/PBI membranes were observed that they showed higher than that of the pristine PBI. The proton conductivities of pristine PBI was ranged from $2.11 \times 10^{-4}$ to $8.99 \times 10^{-4} \mathrm{~S} \mathrm{~cm}^{-1}$ and the proton conductivities of CHS-WSiA (dry)/PBI and CHS-WSiA(wet)/PBI showed from $2.79 \times 10^{-4}$ to $1.104 \times 10^{-3} \mathrm{~S} \mathrm{~cm}^{-1}$ and $1.78 \times 10^{-4}$ to $1.302 \times 10^{-3} \mathrm{~S} \mathrm{~cm}^{-1}$ respectively. Especially, CHS-WSiA(wet)/PBI membrane showed high conductivity above $110{ }^{\circ} \mathrm{C}$ that compared with CHS-WSiA(dry)/PBI membrane and pristine PBI. These observations suggested that CHS-WSiA composite membranes with nano-scale composites maintain acid and water retention properties comparing with pristine PBI membrane for enhancing the proton conductivity after adsorbing PA. 


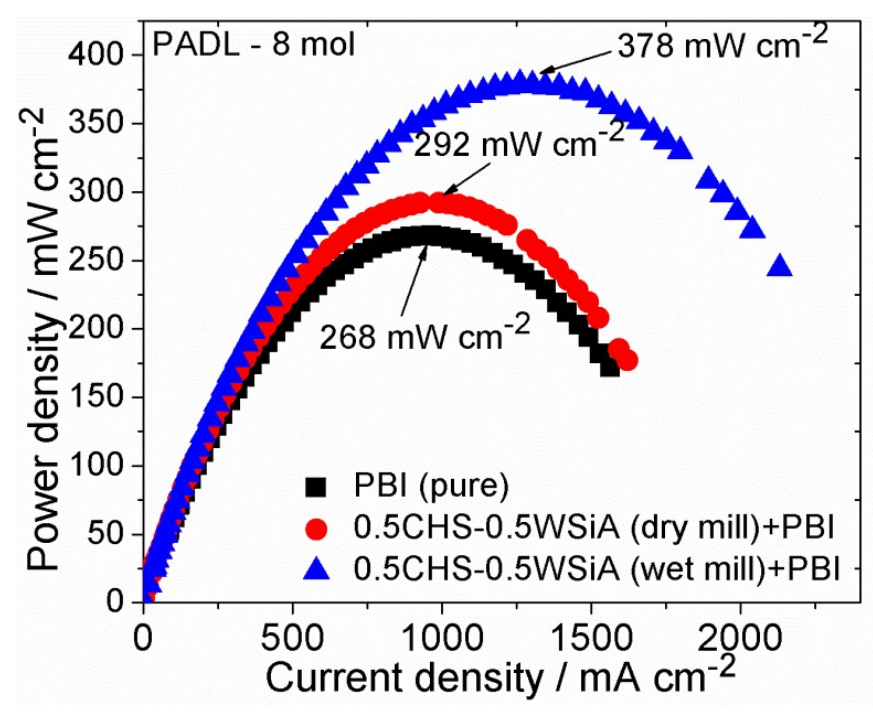

Fig. 8. Power density curves of pristine PBI membrane, $0.5 \mathrm{CHS}-0.5 \mathrm{WSiA}$ (dry mill) /PBI and 0.5 CHS-0.5WSiA(wet mill) / PBI composite membranes under anhydrous condition.

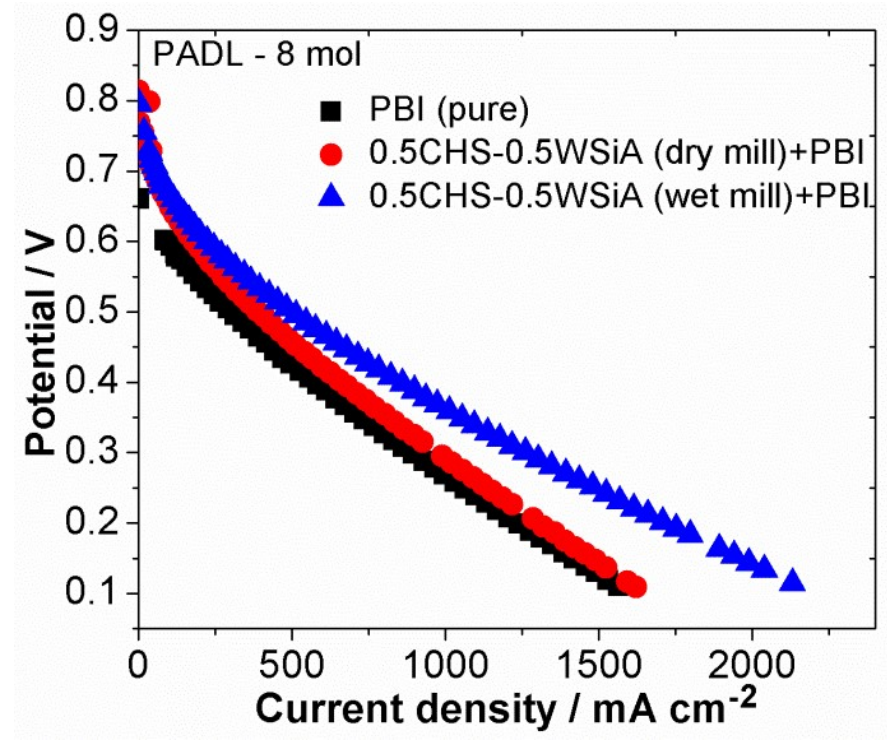

Fig. 9. Polarization curve of pristine PBI membrane, 0.5CHS-0.5WSiA (dry mill) /PBI and 0.5CHS$0.5 \mathrm{WSiA}$ (wet mill)/PBI composite membranes under anhydrous condition. 


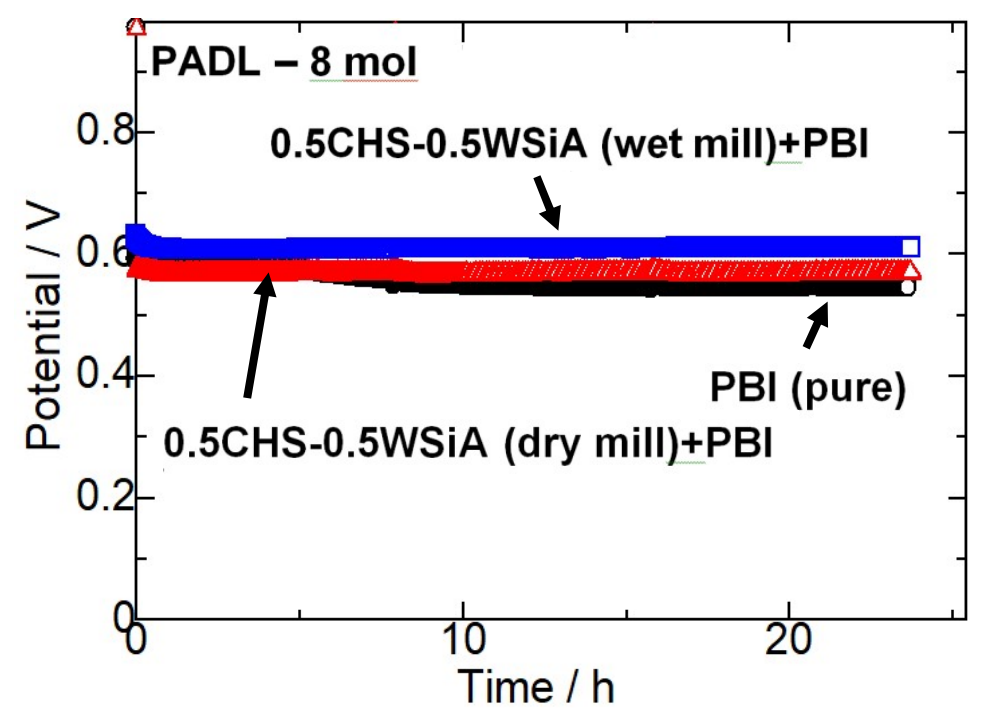

Fig. 10. Constant current density measurement of pristine PBI membrane, 0.5CHS-0.5WSiA (dry mill)/PBI and 0.5CHS-0.5WSiA(wet mill)/PBI composite membranes under anhydrous condition.

The fuel cell evaluation of electrolyte membranes was performed according to their results (shown in Fig. 8 and Fig. 9) ; with highest power density values of 268, 292, and $378 \mathrm{~mW}$ $\mathrm{cm}^{-2}$ for pristine PBI, CHS-WSiA(dry)/PBI, and CHS-WSiA(wet)/PBI, respectively. While CHS-WSiA/PBI membranes showed the open circuit voltages $(>0.8 \mathrm{~V})$ for low gas permeability, pristine PBI showed the open circuit voltage less than $0.8 \mathrm{~V}$. To make the comparison between CHS-WSiA/PBI membranes and pristine PBI in Fig. 8 and 9, it can be seen that all the CHS-WSiA/PBI membrane fuel cells showed good performance compared with pristine PBI. Thus, the CHS-WSiA components in the PBI matrix emphatically adsorbed and retained the PA acid groups in their CHS-WSiA/PBI composite membranes to enhance proton conduction mechanism and prevent acid leaching problem.

The current stability tests of 20 wt \% of CHS-WSiA/PBI composite membranes and pristine $\mathrm{PBI}$ were measured to make confirmation of the acid retention properties and thermal stability of the CHS-WSiA composites/PBI matrix (shown in Fig. 10). The stability tests of composite membranes and pristine PBI were performed as fixed current measurements $\left(0.2 \mathrm{~A} / \mathrm{cm}^{-2}, 24 \mathrm{~h}\right)$. While 20 wt \% CHS-WSiA/PBI composite membranes showed constant potential condition throughout the constant current measurement $(0.2 \mathrm{~A}$ $\mathrm{cm}^{-2}$ ), the pristine one was observed for the degradation of potential after $8 \mathrm{~h}$ measurement. These observation of cell performances suggested that inorganic composites partly supported to the PA acid retention of the adsorbed PA ligands via to new proton conduction of CHS-WSiA composites/PBI matrix.

Thus, the grain nanostructures of the CHS-WSiA composites with grain nano-sized particles by wet milling in the PBI matrix supported to be homogeneously dispersed in the membrane matrix and also created new proton conduction path after adsorption of PA [26].

\section{Conclusions}

CHS-WSiA composites were successfully fabricated via dry and wet mechanical milling, and characterized using XRD, FE-SEM, and proton conductivity measurements. The 
diffraction peaks of these composites shifted to a higher angle via an ion-exchange reaction from a mechanochemical efffect. The grain sizes (about $20 \mathrm{~nm}$ ) of CHS-WSiA composite obtained by wet milling are smaller than the composite obtained by dry milling. From conductivity measurement, CHS-WSiA composite (wet milling) showed higher conductivity of about $10^{-3} \mathrm{~S} \mathrm{~cm}^{-1}$, compared to the raw substances at low temperatures. Inorganic-organic CHS-WSiA/PBI membranes were observed for enhanced adsorption and retention properties of $\mathrm{PA}$ in the medium temperature $\left(100-200{ }^{\circ} \mathrm{C}\right)$ fuel cell evaluation via new proton conduction path of CHS-WSiA composites. CHS-WSiA/PBI membranes showed higher performances with $378 \mathrm{~mW} \mathrm{~cm}^{-2}$ for CHS-WSiA(wet)/PBI and $292 \mathrm{~mW} \mathrm{~cm}^{-2}$ for CHS-WSiA(dry)/PBI in comparing with $268 \mathrm{~mW} \mathrm{~cm}^{-2}$ of pristine PBI membrane. For constant current test, CHS-WSiA/PBI composite membranes showed stable potential over $24 \mathrm{~h}$ period while the potential of pristine PBI was decreased after $8 \mathrm{~h}$. Among membranes, CHS-WSiA(wet)/PBI showed fast PA doping compared with CHSWSiA(dry)/PBI and pristine PBI. Addition of inorganic solid acid complex with high proton conductivity caused fast proton transfer in these composites/PBI electrolyte membranes. Both CHS-WSiA/PBI electrolyte membranes showed proton conductivities higher than pristine PBI. A new proton conduction path was also proposed in these composite membranes due to the inorganic solid composites's effect in the PBI matrix. CHS-WSiA(wet)/PBI showed the highest power density and best durability test with high potential stability among these electrolyte membranes because it showed a stable performance even in a second cycle fuel cell performance measurement by suppressing of PA leaching.

\section{Acknowledgements}

This research work was done by the supports from JSPS Grants-in-Aid for Scientific Research A (26249097), JSPS Grants-in-Aid for Scientific Research A (18H03841), and AUN/SEED-Net (JICA).

\section{References}

1. N. Abdullah, S.K. Kamarudin, J. Power Sources. 278, 109-118 (2015).

2. M. Mizuno, S. Hayashi, Solid State Ionics, 167, 317-323 (2004).

3. O. Barron, H. Su, V. Linkov, B. G. Pollet, S. Pasupathi, J App Electrochem. 44, 10371045 (2014).

4. Q. Li, R. He, J. O. Jensen, N. J. Bjerrum, Fuel cells. 4, 147-159 (2004).

5. J. Loboto, P. Caňizares. M.A. Rodrigo, J.J. Linares, J. A. Aguilar, J. Membr. Sci. 306, 47-55 (2007).

6. A. Matsuda, T. Kanzaki, K. Tadanaga, M. Tatsumisago, T. Minami, Electrochim. Acta. 47, 939-944 (2001).

7. A. Matsuda, T. Kanzaki, K. Tadanaga, M. Tatsumisago, T. Minami, Solid State Ionics. 139, 113-119 (2001).

8. N. Nakamoto, A. Matsuda, K. Tadanaga, T. Minami, M. Tatsumisago, J. Power Sources. 138, 51-55 (2004).

9. K. Tadanaga, H. Yoshida, A. Matsuda, T. Minami, M. Tatsumisago, Electrochim. Acta. 50, 705-708 (2004).

10. Y. Oono, T. Fukuda, A. Sounai, M. Hori, J. Power Sources. 195, 1007-1014 (2010).

11. J. Lablo, P. Caňizares, M. A. Rodrigo, D. Úbeda, F. Javier Pinar. J. Membr. Sci. 369, 105-111 (2011). 
12. F. J. Pinar, P. Caňizares, M. A. Rodrigo, D. Ubeda and J. Lobato, RSC Advances. 2, 1547-1556 (2012).

13. S. Yuk, D-H. Lee, S. Choi, G. Doo, D. W. Lee, H-Tak. Kim, Electrochim Acta. 270, 402-408 (2018).

14. J. Halter, S. Thomas, S. K. Kær, T. J. Schmidt, F. N. Büchi. J. Power Sources. 399, 151-156 (2018).

15. D. Ergun, Y. Devrim, N. Bac, I. Eroglu. J. Applied Polymer Science. 124, E267-E277 (2012).

16. S-Y. Oh, T. Yoshida, G. Kawamura, H. Muto, M. Sakai, A. Matsuda, J. Mat. Chem. 20, 6359-6366 (2010).

17. Y. Daiko, H. Takagi, K. Katagiri, H. Muto, M. Sakai, A. Matsuda, Solid State Ionics. 179, 1174-1177 (2008).

18. S. Shanmugam, B. Viswanathan, T.K. Varadarajan, J. Membr. Sci, 275, 105-109 (2006).

19. S.Y. Oh, T. Yoshida, G. Kawamura, H. Muto, M. Sakai, A. Matsuda, J. Power Sources. 195, 5822-5828 (2010).

20. A. Matsuda, V.H. Nguyen, Y. Daiko, H. Muto, M. Sakai, Solid State Ionics. 181, 180182 (2010).

21. E. Y. Safronova, A.K. Osipov, A. E. Baranchikov, A.B. Yaroslavtsev. Inorg. Mat. 51, 1157-1162 (2015).

22. Suryani, Y-L. Liu, J. Membr. Sci. 332, 121-128 (2009).

23. A. Matsuda, S-Y. Oh, V.H. Nguyen, Y. Daiko, G. Kawamura, H. Muto. Electrochim. Acta. 56, 9364-9369 (2011).

24. J. Mbah, B. Krakow, E. Stefanakos, J. Wolan, Electrochem. and Solid-State Letters. 12, E12-E16 (2009).

25. C. Xu, X. Wu, X. Wang, M. Mamlouk, K. Scott, J. Mater. Chem. 21, 6014-6019 (2011).

26. K. Z. Ya, K. Kumazawa, G. Kawamura, H. Muto, A. Matsuda, J. Ceram. Soc. Jpn. 126, 789-793 (2018). 